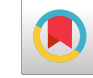

\title{
Vitamin C Improves Passive Avoidance Learning and Memory in Rats Exposed to Radiofrequency Waves Generated by a Base Transceiver Station (BTS) Antenna Model
}

\author{
Gholamali Jelodar ${ }^{1,{ }^{*}}$, Fatemeh Soleimani ${ }^{1}$ and Mansour Azimzadeh (iD ${ }^{1}$ \\ ${ }^{1}$ Department of Physiology, School of Veterinary Medicine, Shiraz University, Shiraz, Iran \\ "Corresponding author: Department of Physiology, School of Veterinary Medicine, Shiraz University, Shiraz, Iran. Email: jelodar@shirazu.ac.ir
}

Received 2018 June 06; Revised 2018 October 11; Accepted 2018 October 23.

\begin{abstract}
Background: Hazardous health effects of the exposure to radiofrequency waves (RFWs) have become of great public concern and impaired memory has been reported following the exposure to electromagnetic radiations.

objectives: As the deleterious effects of the RFW on passive avoidance learning and memory had already been reported, the aim of this study was to evaluate the prophylactic effect of vitamin $C$ on this activity.

Methods: 20 male Sprague-Dawley rats $(230 \pm 20 \mathrm{~g})$ were divided randomly into four groups as: control, control-exposed (exposed to $900 \mathrm{MHz}$ RFW), control treatment (without exposure to RFW receiving $250 \mathrm{mg} / \mathrm{kg}$ of body weight/day L-ascorbic acid by gavage), and treatment (exposed to 900MHz RFW receiving the abovementioned dose of vitamin C) groups. The exposure was performed for 30 consecutive days ( $4 \mathrm{~h} /$ day). Learning and memory were evaluated in the last day by the shuttle box and expressed as the period of remaining within the light area; this time was called "light time".

Results: The exposure to RFW significantly decreased the duration of light time in the control-exposed group compared to the other three groups $(\mathrm{P}<0.05)$. In the fourth group, vitamin $\mathrm{C}$ significantly increased the light time compared to the control-exposed group $(\mathrm{P}<0.05)$. No significant difference was observed between control, control treatment, and treatment groups.

Conclusions: Exposure to RFW significantly altered the passive avoidance behavior. Vitamin C probably due to its antioxidant effects has facilitative results on the acquisition and retrieval activities of passive avoidance learning and memory in rats.
\end{abstract}

Keywords: Base Transceiver Station, Radiofrequency Wave, Passive Avoidance Performance, Learning and Memory, Vitamin C

\section{Background}

An unprecedented increase in global communication has led to a dramatic growth in the number of wireless devices such as mobile phones. Hazardous health effects of the exposure to electromagnetic waves (EMW) have become of great public concern. Among the effect of EMW on various body organs, the effect of these waves on the brain is one of the most attractive areas $(1,2)$.

Experimental studies have shown that exposure to EMW from mobile phones may affect the brain by altering oxidant and antioxidant balance (3), change of neurotransmitters (4), or nerve cell damage (5). The hippocampus plays an important role in learning and memory performance. It has been suggested that the radiofrequency wave (RFW) affects the activity of the hippocampus in rats (6). Deleterious effects of RFW generated by BTS on the function of the central nervous system have been reported. The role of oxidative stress in this process and the contribution of the weak magnetic field to increasing free radicals have been pointed out in the literature $(7,8)$.

Biological systems may be affected by mobile phone radiation through the formation and increase of reactive oxygen species (ROS) and resultant oxidative stress or through changing the antioxidant defense systems of tissues, which the brain is one of the most important ones (2). In this context, many authors have shown that the exposure to RF from mobile phones causes a marked oxidative damage to brain tissues, accompanied by oxidative stress, as well as, disturbances in the antioxidant defense systems $(9,10)$.

Impairment in learning and memory in response to RF radiations ranging from 900 to $1800 \mathrm{MHz}$ has been widely documented in the literature $(11,12)$. Several studies on non-thermal RF levels from mobile phones have shown impairments in human cognitive performances $(13,14)$; however, others have found no changes $(15,16)$. Studies on ani- 
mal learning and memory have reported significantly reduced memory functions due to the exposure to mobile phone radiation $(17,18)$ although others have not corroborated $(19,20)$.

Vitamin C or L-ascorbic acid has antioxidant activities owing to 2, 3-enediol in its structure (21). Its supplement has particularly beneficial effects in pathological conditions (22). It is well accepted that the most abundant watersoluble antioxidant in biological fluids is vitamin C, which is essential for protection against diseases and degenerative processes caused by oxidative stress $(23,24)$.

Several functions have been known for intracellular ascorbate including (1) antioxidant protection, (2) amination of peptides, (3) myelin formation, (4) synaptic strengthening, and (5) protection against glutamate toxicity. It has been shown that ascorbate may protect the nerve cells from damage in neuronal degeneration diseases such as Alzheimer's, Parkinson's, and Huntington diseases (25).

Supplementation with vitamin C as an important component of antioxidant defense systems has been proposed to prevent memory deficits and cognitive dysfunction and enhance learning and memory (26). On the other hand, it has been reported that in early postnatal life, vitamin C deficiency leads to impaired neuronal development and a functional decrease in spatial memory (27).

The deleterious effect of RFW on learning and memory has been shown in our laboratory (28). Furthermore, there are reports on the protective role of vitamin $C$ in the rat brain following the exposure to RFW generated by a BTS (29). Hence, this study was conducted to evaluate the effect of Vitamin C on passive avoidance learning and memory in rats exposed to radiofrequency waves.

\section{Methods}

\subsection{Animal Experiments}

All of the procedures were conducted in accordance with the "guiding principles for the care and use of research animals" approved by the Shiraz University. 20 male Sprague-Dawley rats (230 \pm 20 g, age 5 - 8 weeks) colonybred at the animal house center were housed in plastic cages $(42 \times 26.5 \times 15 \mathrm{~cm})$ under controlled light/dark $(12 / 12)$ and temperature $\left(20 \pm 2{ }^{\circ} \mathrm{C}\right)$ with free access to food and water.

\subsection{Radiofrequency Signal Generator}

To produce $900 \mathrm{MHz}$ signals, a generator with an output power density of $0.6789 \mathrm{~mW} / \mathrm{cm}^{2}$ was used in the Department of Electrical Engineering, Shiraz University, and its output was monitored by a spectrum analyzer (FSH6, from Rohde and Schwarz, Germany). Exposure to $900 \mathrm{MHz}$ was done at the average power density of $86 \mathrm{~mW} / \mathrm{cm}^{2}(22.8$ $-146.8 \mathrm{~mW} / \mathrm{cm}^{2}$ ) with the average whole body and brainspecific absorption rate (SAR) of $0.19-1.22 \mathrm{~W} / \mathrm{kg}$ and 0.013 $\mathrm{W} / \mathrm{kg}$, respectively. The rat's cages of groups 2 and 4 were placed $1 \mathrm{~m}$ away from the signal generator.

\subsection{Experimental Design}

The effect of RFW (900 MHz) on passive avoidance learning and memory of animals and the effect of vitamins $\mathrm{C}$ were evaluated by dividing 20 rats into four equal groups, and the treatment was given orally, as follows:

Group1: The control group received the vehicle, i.e., distilled water.

Group 2: The control exposed group was exposed to RFW of $900 \mathrm{MHz}$ (received vehicle, i.e., distilled water).

Group 3: The control treatment group received 250 $\mathrm{mg} / \mathrm{kg}$ of body weight (BW)/day of vitamin C by gavage for 30 consecutive days, without any exposure.

Group 4: The treatment group received vitamin C (250 $\mathrm{mg} / \mathrm{kg}$ BW/day) orally by gavage before exposure to RFW.

Groups 2 and 4 were exposed to the RFW 4 h/day (between 9 A.M. and 1 P.M.) during a period of 30 consecutive days. The control and control treatment groups were placed in the same conditions without applying the RFW. At the end of the duration, learning and memory tests were conducted by the shuttle box.

\subsection{Passive Avoidance Apparatus}

A shuttle-box $(44 \times 20 \times 19 \mathrm{~cm})$ was used with acrylic walls and steel floor bars (manufactured by Aryoazma Co.). By a vertical partition, the box was bisected into light and dark compartments with an opening in the median that allowed the animals to move freely from one part to another. The light section was safe for animals while a foot shock of $0.6 \mathrm{~mA}$ for one second with a latent period of one second was applied in the dark compartment.

\subsection{Procedure}

The passive avoidance test was conducted by the method described by Bures et al. (30), with modifications. On day one, each of the rats was individually subject to two minutes of conformity with the shuttle box, in which the rat could move about freely. The dark compartment was the favorite place for the rat; thus, if the rat did not move to the dark compartment after 120 seconds, it was eliminated from the experiment. This adaptation was repeated 30 minutes later. On day two, the rats were placed in the light compartment and one second after entering the dark compartment, they received a $0.6 \mathrm{~mA}$ foot shock for one second. The third day was analogous to the second day and it was considered as learning. On day four, considered as 
memory consolidation, the action was similar to that of the learning days without foot shock. On day five, regarded as memory retention, the protocol was the same as that of day four. If the rats did not move to the dark section after 120 seconds during the third, fourth, and fifth meetings of experiments, they were known as completely learned (30).

\subsection{Statistical Analysis}

The obtained data, presented as mean \pm SEM, were analyzed by Statistical Package for Social Sciences (SPSS, version 16.0). In addition, they were analyzed separately for each group with the Kruskal-Wallis nonparametric test. In case of significant results by Kruskal-Wallis test (Table 1), pairwise comparisons were made using Mann-Whitney test (Table 2). A value of $\mathrm{P}<0.05$ was considered statistically significant.

\begin{tabular}{lccc}
\hline \multicolumn{4}{l}{ Table 1. The Kruskal-Wallis Test } \\
\hline Timar & Learning & Consolidation & Retention \\
\hline Chi-square & 12.2235 & 12.4904 & 14.4313 \\
DF & 3 & 3 & 3 \\
Asymp. significance & 0.006 & 0.005 & 0.002 \\
\hline
\end{tabular}

\section{Results}

The mean values ( \pm SEM) of the passive avoidance learning and memory are presented in Figures 1 - 3. On the learning session (Figure 1), the control exposed group spent minimum time ( $48 \mathrm{sec}$ ) while the other groups with significant differences spent much longer time (more than $115 \mathrm{sec}$ ) in the light area. The value of memory consolidation time is presented in Figure 2, which is minimum (53.4 sec) for the control exposed group and more than $114 \mathrm{sec}$ in the other groups with significant differences. Memory retention time significantly decreased following exposure to RFW compared to the other groups (63 sec vs. 114 - 120 sec) (Figure 3). Exposure to RFW significantly decreased the time spent in the light compartment in the control exposed group compared to other groups $(\mathrm{P}<0.05)$; however, the administration of vitamin $C$ to the fourth group significantly increased the time spent in the light compartment and brought its value to normal range with no significant difference compared to the control group in all sessions of the test $(\mathrm{P}<0.05)$. The exposed group was significantly different from the other groups but there were no significant differences between the other study groups $(\mathrm{P}$ $>0.05)$.

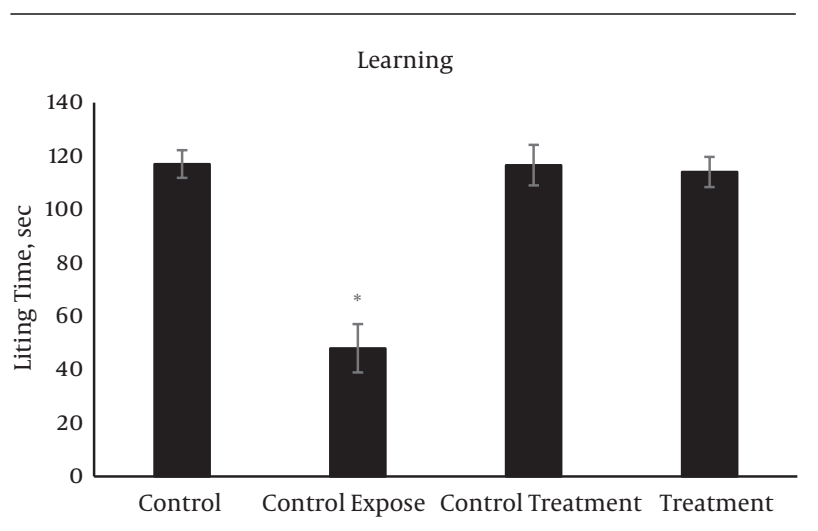

Figure 1. Comparison of mean ( \pm SEM) lighting time (as the index of memory and learning) in control, control exposed, control treatment, and treatment groups during learning. Asterisk shows a significant difference compared to other groups $(\mathrm{P}<$ $0.05)$.

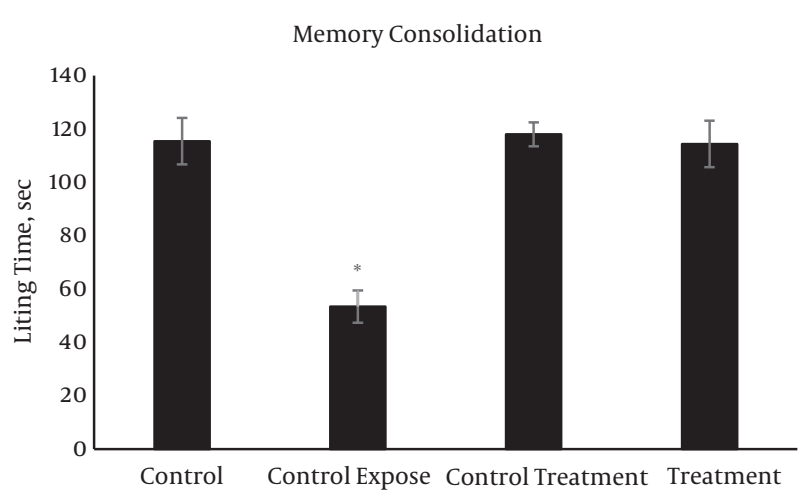

Figure 2. Comparison of mean ( \pm SEM) lighting time (as the index of memory and learning) in control, control exposed, control treatment, and treatment groups during memory consolidation. Asterisk shows a significant difference compared to other groups $(\mathrm{P}<0.05)$.

\section{Discussion}

In the present study, exposure to $900 \mathrm{MHz}$ waves caused a significant reduction in passive avoidance learning. Furthermore, the oral administration of vitamin $C$ caused a significant increase in learning, memory consolidation, and retention.

Exposure to RFW may impair passive avoidance learning and memory through various mechanisms such as (1) oxidative stress and the production of reactive oxygen species (3, 31), (2) excitation of hippocampal cells, changes in morphology and hippocampal degeneration and destruction of nerve cells $(32,33)$, and (3) changes in the glial cells (34).

The ROS are directly involved in damage to cellular macromolecules, such as lipids, proteins, and nucleic acids in tissues (35). Exposure to mobile phone radiofrequency 


\begin{tabular}{|c|c|c|c|}
\hline & Learning & Memory Consolidation & Memory Retention \\
\hline \multicolumn{4}{|c|}{ Control vs. Exposed Group } \\
\hline $\mathbf{Z}$ & -2.643 & -2.643 & -2.694 \\
\hline Asymp. significance $^{\mathrm{a}}$ & 0.008 & 0.008 & 0.007 \\
\hline \multicolumn{4}{|c|}{ Control Treatment vs. Exposed Group } \\
\hline $\mathbf{Z}$ & -2.694 & -2.694 & -2.785 \\
\hline Asymp. significance ${ }^{a}$ & 0.007 & 0.007 & 0.005 \\
\hline \multicolumn{4}{|c|}{ Treatment vs. Exposed Group } \\
\hline $\mathbf{Z}$ & -2.619 & -2.643 & -2.643 \\
\hline Asymp. significance $^{a}$ & 0.009 & 0.008 & 0.008 \\
\hline
\end{tabular}

${ }^{\text {a }}$ Statistical significance by Mann-Whitney's U-test is shown at $\mathrm{P}<0.05$.

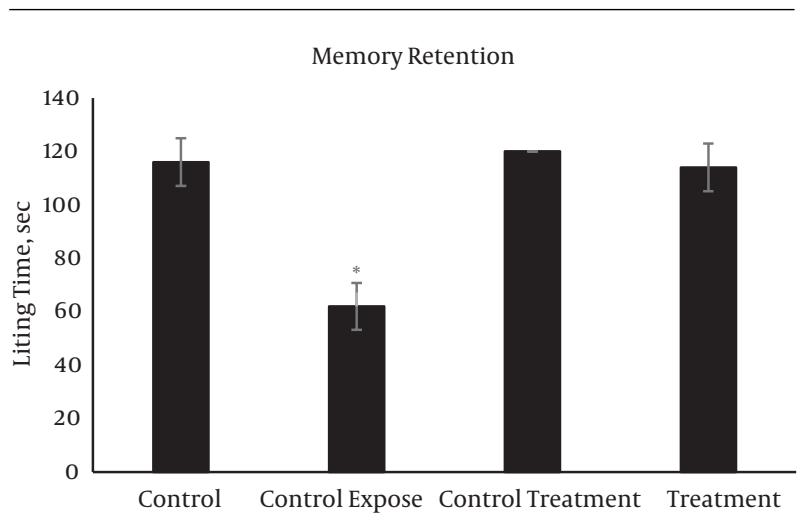

Figure 3. Comparison of mean ( \pm SEM) lighting time (as the index of memory and learning) in control, control exposed, control treatment, and treatment groups during memory retention. Asterisk shows a significant difference compared to other groups $(\mathrm{P}<0.05)$

waves may increase free radicals in biological systems by elevating lipid peroxidation or changes in the antioxidant defense system $(9,36)$.

It has been shown that the brain is deficient in oxidative defense and therefore is more vulnerable to be affected by reactive oxygen species resulting in dysfunction at the cellular and molecular levels (37).

Furthermore, oxidative stress and increased ROS levels in the central nervous system have been reported to link to neurodegenerative disorders such as Alzheimer's disease, Parkinson's disease, and amyotrophic lateral sclerosis (38).

It is well accepted that vitamin $C$ is the potent antioxidant (39) in biological fluids for protection against degenerative processes of oxidative stress in the brain and other tissues $(3,23,24,40)$.

It was suggested that ascorbic acid could affect passive avoidance learning and memory by changes in neuronal activity in the hippocampus (41). In addition, reports indicate that oxidative damage to the rats' cortical and hippocampal synapses is involved in cognitive function defects that might be prevented by the consumption of antioxidants $(32,42)$. The hippocampus is a brain structure and is involved in many types of learning and memory. It has been shown that intrahippocampal injection of vitamin C improves memory for passive avoidance learning (43). Furthermore, it has been reported that exposure to radiation can affect hippocampal cell morphology and function in the brain region, which controls important behavioral and cognitive functions (44).

It has been shown that neurons and glia interact and possess the ability to process information and behavior (34). The poor performance of rats in behavior may be because of devastating effects of microwave radiation on glial cells, which, in turn, alter neuronal activity in the hippocampus and amygdala in rats (45). Vitamin C prevented the destructive effects of microwave radiation on glial cells and thus prevented the poor performance of rats in these experiments.

Moreover, the increased levels of ROS may cause an increase in apoptosis (35); however, vitamin $C$ reduces free radicals formation and may prevent the apoptosis of the cells and impairment of passive avoidance learning following exposure to RFW.

\subsection{Conclusions}

We, therefore, conclude that mobile phone radiation could impair learning and memory. In addition, the administration of vitamin $C$ possibly via its antioxidant role improves learning and memory performance in animals exposed to RFW. 


\section{Acknowledgments}

We acknowledge Mrs. Ahmadi for her assistant in laboratory work.

\section{Footnotes}

Conflict of Interests: The authors report no declaration of interest. The authors alone are responsible for the content and writing of the paper.

Ethical Considerations: This research has been approved by Postgraduate Committee of School of Veterinary Medicine.

Funding/Support: This study was part of an MSc. thesis and was supported financially by the Vice Chancellor for research affairs of Shiraz University.

\section{References}

1. Cardis E, Deltour I, Mann S, Moissonnier M, Taki M, Varsier N, et al. Distribution of RF energy emitted by mobile phones in anatomical structures of the brain. Phys Med Biol. 2008;53(11):2771-83. doi:10.1088/00319155/53/11/001. [PubMed: 18451464].

2. Sokolovic D, Djindjic B, Nikolic J, Bjelakovic G, Pavlovic D, Kocic G, et al. Melatonin reduces oxidative stress induced by chronic exposure of microwave radiation from mobile phones in rat brain.J Radiat Res. 2008;49(6):579-86. doi:10.1269/jrr.07077. [PubMed: 18827438].

3. Akbari A, Jelodar G, Nazifi S. The prophylactic effect of vitamin C on oxidative stress indexes following exposure to radio frequency wave generated by a BTS antenna model in rat liver and kidney. Zahedan J Res Med Sci. 2014;16(2):19-23.

4. Tamasidze AG, Nikolaishvili MI. [Effect of high-frequency EMF on public health and its neuro-chemical investigations]. Georgian Med News. 2007;(142):58-60. Russian. [PubMed: 17327637].

5. Salford LG, Brun AE, Eberhardt JL, Malmgren L, Persson BRR. Nerve cell damage in mammalian brain after exposure to microwaves from GSM mobile phones. Environ Health Perspect. 2003;111(7):881-883. doi: 10.1289/ehp.6039. [PubMed: 12782486]. [PubMed Central: PMC1241519].

6. Ammari M, Gamez C, Lecomte A, Sakly M, Abdelmelek H, De Seze R. GFAP expression in the rat brain following sub-chronic exposure to a $900 \mathrm{MHz}$ electromagnetic field signal. Int J Radiat Biol. 2010;86(5):36775. doi: 10.3109/09553000903567946. [PubMed: 20397841].

7. Timmel CR, Cintolesi F, Brocklehurst B, Hore PJ. Model calculations of magnetic field effects on the recombination reactions of radicals with anisotropic hyperfine interactions. Chem Phys Lett. 2001;334(46):387-95. doi: 10.1016/S0009-2614(00)01436-6.

8. Akbari A, Jelodar G, Nazifi S. The proposed mechanisms of radio frequency waves (RFWs) on nervous system functions impairment. Compar Clin Pathol. 2016;25(6):1289-301. doi:10.1007/s00580-015-2096-x.

9. Ilhan A, Gurel A, Armutcu F, Kamisli S, Iraz M, Akyol O, et al. Ginkgo biloba prevents mobile phone-induced oxidative stress in rat brain. Clin Chim Acta. 2004;340(1-2):153-62. [PubMed: 14734207].

10. Meral I, Mert H, Mert N, Deger Y, Yoruk I, Yetkin A, et al. Effects of 900-MHz electromagnetic field emitted from cellular phone on brain oxidative stress and some vitamin levels of guinea pigs. Brain Res. 2007;1169:120-4. doi: 10.1016/j.brainres.2007.07.015. [PubMed: 17674954].

11. Megha K, Deshmukh PS, Banerjee BD, Tripathi AK, Abegaonkar MP. Microwave radiation induced oxidative stress, cognitive impairment and inflammation in brain of Fischer rats. Indian J Exp Biol. 2012;50(12):889-96. [PubMed: 23986973].
12. Narayanan SN, Kumar RS, Potu BK, Nayak S, Mailankot M. Spatial memory performance of Wistar rats exposed to mobile phone. Clinics (Sao Paulo). 2009;64(3):231-4. [PubMed: 19330250]. [PubMed Central: PMC2666459].

13. Keetley V, Wood AW, Spong J, Stough C. Neuropsychological sequelae of digital mobile phone exposure in humans. Neuropsychologia.2006;44(10):1843-8. doi:10.1016/j.neuropsychologia.2006.03.002. [PubMed: 16616941].

14. Maier R, Greter SE, Schaller G, Hommel G. [The effects of pulsed lowlevel EM fields on memory processes]. Z Med Phys. 2004;14(2):105-12. German. [PubMed: 15323288].

15. Haarala C, Takio F, Rintee T, Laine M, Koivisto M, Revonsuo A, et al. Pulsed and continuous wave mobile phone exposure over left versus right hemisphere: Effects on human cognitive function. Bioelectromagnetics. 2007;28(4):289-95. doi: 10.1002/bem.20287. [PubMed: 17203481]

16. Russo R, Fox E, Cinel C, Boldini A, Defeyter MA, Mirshekar-Syahkal $D$, et al. Does acute exposure to mobile phones affect human attention? Bioelectromagnetics. 2006;27(3):215-20. doi: 10.1002/bem.20193. [PubMed: 16304701].

17. Nittby H, Grafstrom G, Tian DP, Malmgren L, Brun A, Persson BR, et al. Cognitive impairment in rats after long-term exposure to GSM-900 mobile phone radiation. Bioelectromagnetics. 2008;29(3):219-32. doi: 10.1002/bem.20386. [PubMed: 18044737].

18. Wang B, Lai H. Acute exposure to pulsed 2450-MHz microwaves affects water-maze performance of rats. Bioelectromagnetics. 2000;21(1):52-6. [PubMed: 10615092].

19. Cobb BL, Jauchem JR, Adair ER. Radial arm maze performance of rats following repeated low level microwave radiation exposure. Bioelectromagnetics. 2004;25(1):49-57. doi: 10.1002/bem.10148. [PubMed: 14696053].

20. Dubreuil D, Jay T, Edeline JM. Head-only exposure to GSM $900-\mathrm{MHz}$ electromagnetic fields does not alter rat's memory in spatial and nonspatial tasks. Behav Brain Res. 2003;145(1-2):51-61. doi: 10.1016/S01664328(03)00100-1.

21. Lee J, Koo N, Min DB. Reactive oxygen species, aging, and antioxidative nutraceuticals. Compr Rev Food Sci F. 2004;3(1):21-33. doi: 10.1111/j.15414337.2004.tbo0058.x.

22. Grosso G, Bei R, Mistretta A, Marventano S, Calabrese G, Masuelli L, et al. Effects of vitamin $\mathrm{C}$ on health: A review of evidence. Front Biosci (Landmark Ed). 2013;18:1017-29. [PubMed: 23747864].

23. Jelodar G, Akbari A, Nazifi S. The prophylactic effect of vitamin C on oxidative stress indexes in rat eyes following exposure to radiofrequency wave generated by a BTS antenna model. Int J Radiat Biol. 2013;89(2):128-31. doi: 10.3109/09553002.2012.721051. [PubMed: 22892052].

24. Jelodar G, Nazifi S, Akbari A. The prophylactic effect of vitamin C on induced oxidative stress in rat testis following exposure to 900 $\mathrm{MHz}$ radio frequency wave generated by a BTS antenna model. Electromagn Biol Med. 2013;32(3):409-16. doi: 10.3109/15368378.2012.735208. [PubMed: 23323690].

25. Cay M, Nazırog- lu M, Simsek H, Aydilek N, Aksakal M, Demirci M. Effects of intraperitoneally administered vitamin C on antioxidative defense mechanism in rats with diabetes induced by streptozotocin. Res Exp Med (Berl). 2001;200(3):205-13. [PubMed: 11426672].

26. Delwing D, Bavaresco CS, Monteiro SC, Matte C, Netto CA, Wyse AT. alpha-Tocopherol and ascorbic acid prevent memory deficits provoked by chronic hyperprolinemia in rats. Behav Brain Res. 2006;168(2):185-9. doi:10.1016/j.bbr.2005.08.014. [PubMed:16214240].

27. Tveden-Nyborg P, Johansen LK, Raida Z, Villumsen CK, Larsen JO, Lykkesfeldt J. Vitamin C deficiency in early postnatal life impairs spatial memory and reduces the number of hippocampal neurons in guinea pigs. Am J Clin Nutr. 2009;90(3):540-6. doi: 10.3945/ajcn.2009.27954. [PubMed: 19640959]. 
28. Azimzadeh M, Jelodar G, Namazi F, Soleimani F. Exposure to radiofrequency wave (RFW) generated by a base transceiver stations (BTS) antenna model affects learning and memory in females more than males. Int J Radiat Res. 2017;In press:11-251.

29. Akbari A, Jelodar G, Nazifi S. Vitamin C protects rat cerebellum and encephalon from oxidative stress following exposure to radiofrequency wave generated by a BTS antenna model. Toxicol Mech Methods. 2014;24(5):347-52. doi: 10.3109/15376516.2014.910852. [PubMed: 24730455].

30. Bures J, Burešová $\mathrm{O}$, Huston JP. Techniques and basic experiments for the study of brain and behavior. Amsterdam, New York: Elsevier Science; 1983.

31. Kesari KK, Kumar S, Behari J. 900-MHz microwave radiation promotes oxidation in rat brain. Electromagn Biol Med. 2011;30(4):219-34. doi: 10.3109/15368378.2011.587930. [PubMed: 22047460].

32. Fukui K, Omoi NO, Hayasaka T, Shinnkai T, Suzuki S, Abe K, et al. Cognitive impairment of rats caused by oxidative stress and aging, and its prevention by vitamin E. Ann NYAcad Sci. 2002;959:275-84. [PubMed: 11976202].

33. Narayanan SN, Kumar RS, Potu BK, Nayak S, Bhat PG, Mailankot M. Effect of radio-frequency electromagnetic radiations (RF-EMR) on passive avoidance behaviour and hippocampal morphology in Wistar rats. Ups J Med Sci. 2010;115(2):91-6. doi: 10.3109/03009730903552661. [PubMed: 20095879]. [PubMed Central: PMC2853785].

34. Laming PR, Kimelberg H, Robinson S, Salm A, Hawrylak N, Muller C, et al. Neuronal-glial interactions and behaviour. Neurosci Biobehav Rev. 2000;24(3):295-340. [PubMed:10781693].

35. Kivrak EG, Yurt KK, Kaplan AA, Alkan I, Altun G. Effects of electromag netic fields exposure on the antioxidant defense system. J Microsc $\mathrm{Ul}$ trastruct. 2017;5(4):167-76. doi: 10.1016/j.jmau.2017.07.003. [PubMed: 30023251]. [PubMed Central: PMC6025786].

36. Ozguner F, Oktem F, Ayata A, Koyu A, Yilmaz HR. A novel antioxidant agent caffeic acid phenethyl ester prevents long-term mobile phone exposure-induced renal impairment in rat. Prognostic value of malondialdehyde, N-acetyl-beta-D-glucosaminidase and nitric oxide determination. Mol Cell Biochem. 2005;277(1-2):73-80. doi:10.1007/s11010005-5074-9. [PubMed: 16132717].
37. Gupta YK, Gupta M, Kohli K. Neuroprotective role of melatonin in oxidative stress vulnerable brain. Indian J Physiol Pharmacol. 2003;47(4):373-86. [PubMed: 15266948].

38. Butterfield DA, Galvan V, Lange MB, Tang H, Sowell RA, Spilman $\mathrm{P}$, et al. In vivo oxidative stress in brain of Alzheimer disease transgenic mice: Requirement for methionine 35 in amyloid beta-peptide of APP. Free Radic Biol Med. 2010;48(1):136-44. doi 10.1016/j.freeradbiomed.2009.10.035. [PubMed: 19854267]. [PubMed Central: PMC2818480].

39. Monteiro SC, Matte C, Bavaresco CS, Netto CA, Wyse AT. Vitamins $\mathrm{E}$ and $\mathrm{C}$ pretreatment prevents ovariectomy-induced memory deficits in water maze. Neurobiol Learn Mem. 2005;84(3):192-9. doi: 10.1016/j.nlm.2005.08.002. [PubMed:16169259].

40. Imge EB, Kilicoglu B, Devrim E, Cetin R, Durak I. Effects of mobile phone use on brain tissue from the rat and a possible protective role of vitamin C - a preliminary study. Int J Radiat Biol. 2010;86(12):1044-9. doi: 10.3109/09553002.2010.501838. [PubMed: 20698742].

41. Reis EA, Zugno AI, Franzon R, Tagliari B, Matte C, Lammers ML, et al Pretreatment with vitamins $E$ and $C$ prevent the impairment of memory caused by homocysteine administration in rats. Metab Brain Dis. 2002;17(3):211-7. [PubMed:12322790].

42. Fukui K, Onodera K, Shinkai T, Suzuki S, Urano S. Impairment of learning and memory in rats caused by oxidative stress and aging, and changes in antioxidative defense systems. Ann N Y Acad Sci. 2001;928:168-75. [PubMed: 11795507].

43. Babri S, Mehrvash F, Mohaddes G, Hatami H, Mirzaie F. Effect of intrahippocampal administration of vitamin $\mathrm{C}$ and progesterone on learning in a model of multiple sclerosis in rats. Adv Pharm Bull. 2015;5(1):83-7. doi: 10.5681/apb.2015.011. [PubMed: 25789223]. [PubMed Central: PMC4352227].

44. Odaci E, Bas O, Kaplan S. Effects of prenatal exposure to a 900 $\mathrm{MHz}$ electromagnetic field on the dentate gyrus of rats: A stereological and histopathological study. Brain Res. 2008;1238:224-9. doi: 10.1016/j.brainres.2008.08.013. [PubMed: 18761003].

45. Richter-Levin G, Akirav I. Amygdala-hippocampus dynamic interaction in relation to memory. Mol Neurobiol. 2000;22(1-3):11-20. doi: 10.1385/MN:22:1-3:011. [PubMed: 11414274]. 